\title{
HUBUNGAN ANTARA PERAN LINGKUNGAN, MOTIVASI DAN KEPUASAN KERJA TERHADAP DISIPLIN KERJA PEGAWAI DINAS KEPENDUDUKAN DAN PENCATATAN SIPIL KABUPATEN TEMANGGUNG
}

\author{
Waskito Adi \\ Fakultas Ekonomi Universitas Sarjanawiyata Tamansiswa Yogyakarta \\ Email: adiwk123tmg@gmail.com
}

\section{Intisari}

Penelitian ini bertjuan untuk menguji apakah Hubungan Antara Peran Lingkungan, Motivasi dan Kepuasan kerja terhadap Disiplin Kerja Pegawai Dinas Kependudukan Dan Pencatatan Sipil Kab Temanggung. Metode penelitian ini menggunakan deskriptif kuantitatif dan data primer dengan menggunakan kuesioner.

Dalam pengambilan sampel Pegawai Dinas Kependudukan Dan Pencatatan Sipil Kab Temanggung. Teknik pengambilan sampling menggunakan non probability accidental yaitu populasi yang dijadikan sampel adalah setiap orang yang ditemui pada saat itu juga diberi angket permohonan pengisian kuisioner untuk disebarkan lagi kepada responden lain dengan tujuan untuk memperoleh data yang lebih banyak. Jumlah kuesioner yang disebarkan adalah sebanyak 55 kuesioner. Data dianalisis menggunakan SPSS analisis regresi linear berganda.

Hasil penelitian ini menunjukkan bahwa lingkungan dan motivasi kerja tidak berpengaruh postif terhadap disiplin kerja secara parsial, sedangkan lingkungan dan motivasi kerja berpengaruh signifikan terhadap kepuasan kerja (Z) dan disiplin kerja (Y) secara bersama-sama atau simultan.

Kata Kunci: Lingkungan, Motivasi, Kepuasan, Disiplin Kerja

\begin{abstract}
This study aims to examine whether the Relationship between the Role of the Environment, Motivation and Job Satisfaction with the Employee Discipline of the Office of Population and Civil Registration Temanggung District. This research method uses quantitative descriptive and primary data using a questionnaire.

In sampling the Civil Servants and Civil Servants Office of Temanggung District. The sampling technique uses non probability accidental, which is that the population sampled is everyone who is met at that time also given a questionnaire requesting the filling of questionnaires to be distributed again to other respondents in order to obtain data more. The number of questionnaires distributed was 55 questionnaires. Data were analyzed using SPSS multiple linear regression analysis.

The results of this study indicate that work environment and motivation have no positive effect on work discipline partially, while work environment and motivation have a significant effect on job satisfaction (Z) and work discipline $(Y)$ together or simultaneously.
\end{abstract}

Keywords : Environment, Motivation, Satisfaction, Work Discipline

\section{PENDAHULUAN}

Dalam suatu sistem operasi kependudukan, Sumber Daya Manusia pada dasarnya merupakan salah satu modal dan memegang suatu peran yang paling penting dalam mencapai tujuan lembaga atau instansi. Oleh karena itu instansi perlu mengelola Sumber Daya Manusia sebaik mungkin. Instansi harus mampu memiliki Sumber Daya Manusia yang berkualitas. Sumber Daya Manusia merupakan aspek yang krusial untuk menunjang produktivitas sebuah instansi agar mampu mengelola data kependudukan dalam suatu pemerintahan daerah ini. Oleh karena itu, sebuah instansi harus mampu mengelola Sumber Daya Manusianya dengan baik agar dapat 
meningkatkan produktivitas di instansi tersebut. Keberhasilan suatu instansi atau organisasi dalam mencapai suatu tujuan tidak lepas dari peran pegawai. Pegawai bukan sebuah obyek dalam mencapai sebuah tujuan instansi, tetapi juga menjadi subyek atau pelaku. Mereka dapat menjadi perencana, pelaksanaan dan pengendali yang selalu berperan penting dalam mewujudkan tujuan instansi, serta mempunyai pikiran, perasaan dan keinginan yang dapat mempengaruhi sikapnya terhadap pekerjaan. Kemampuan instansi atau organisasi dalam memberdayakan potensi sumber daya manusia juga sangat dibutuhkan dalam era persaingan yang semakin kompetitif sekarang ini. Oleh karena itu penanganan sumber daya manusia (SDM) yang ada, harus dilakukan secara menyeluruh dalam kerangka sistem pengelolaan SDM yang semakin meningkat kemampuan dan keterampilan sehingga mempunyai kinerja yang baik. Tujuan utama MSDM adalah memperoleh individu-individu yang akan memiliki nilai ekonomi bagi instansi, memiliki produktivitas yang tinggi dan memiliki kepuasan kerja. Kepuasan kerja didefinisikan sikap seorang pegawai terhadap puas atau tidak puasnya terhadap pekerjaan. Kepuasan kerja kerja dihasilkan dari persepsi pegawai adalah sifat dasar pekerjaan, penyediaan, upah sekarang, kesempatan promosi, dan hubungan dengan sesama rekan kerja (Afiyah et al. 2017).

Disiplin kerja merupakan sebuah titik awal dari segala kesuksesan dalam rangka mencapai tujuan sebuah organisasi/instansi. Penerapan disiplin kerja dalam suatu organisasi/instansi bertujuan agar semua pegawai yang ada dalam instansi tersebut bersedia dengan sukarela mematuhi serta mentaati setiap tata tertib yang berlaku tanpa ada paksaan. Disiplin kerja yang baik dapat dilihat dari tingginya kesadaran para pegawai dalam mematuhi serta mentaati segala peraturan dan tata tertib yang berlaku, besarnya rasa tanggung jawab akan tugas masing-masing, serta meningkatkan efisiensi dan kinerja para pegawainya.

\section{TINJAUAN PUSTAKA DAN PENGEMBANGAN HIPOTESIS Lingkungan}

Parlinda dan Wahyuddin (2010) dalam penelitiannya menyatakan bahwa kondisi kerja adalah keadaan dimana tempat kerja yang baik meliputi lingkungan fisik dan lingkungan non fisik yang dapat memberikan kesan menyenangkan, aman, tentram dan lain sebagainya (Lumentut \& Dotulong 2015).

\section{Motivasi}

Keinginan dalam diri seseorang yang menyebabkan orang tersebut bertindak. Orang bertindak karena satu alasan yaitu untuk mencapai tujuan. Jadi, motivasi adalah sebuah dorongan yang diatur oleh tujuan dan jarang muncul dalam kekosongan (Fengky et al. 2011).

\section{Kepuasan Kerja}

Kepuasan kerja adalah sikap umum terhadap pekerjaan seseorang, yang menunjukkan perbedaan antara jumlah penghargaan yang diterima pekerja dan jumlah yang mereka yakini saharusnya mereka terima (Manik 2017).

\section{Disiplin}

Disiplin menunjukkan suatu kondisi atau sikap hormat yang ada pada diri karyawan/pegawai terhadap peraturan dan ketetapan sebuah instansi, dengan demikian bila peraturan atau ketetapan yang ada dalam instansi itu diabaikan atau sering dilanggar, maka pegawai mempunyai disiplin kerja yang buruk dalam Sutrisno (2009:86).

\section{Pengembangan Hipotesis}

\section{Pengaruh Lingkungan Terhadap Disiplin Kerja}

Menurut Parlinda dan Wahyuddin (2010) dalam penelitiannya menyatakan bahwa kondisi kerja adalah keadaan dimana tempat kerja yang baik meliputi lingkungan fisik dan lingkungan non fisik yang dapat memberikan kesan menyenangkan, aman, tentram dan lain sebagainya. (Lumentut \& Dotulong 2015). Apabila dikaitkan dengan instansi tempat bekerja, dapat 
dikatakan bahwa lingkungan kerja adalah tempat di mana karyawan melakukan aktivitas setiap harinya. Lingkungan kerja dikatakan baik atau sesuai apabila manusia dapat melaksanakan kegiatan secara optimal, sehat, aman dan nyaman. Dengan demikian, lingkungan memang saling berhubungan atau berperan dengan tingkat disiplin kerja Dinas Kependudukan Dan Pencatatan Sipil Kab. Temanggung, yang mana akan menjadi objek dalam penelitian ini.

H1: Lingkungan kerja yang nyaman diduga berpengaruh signifikan positif $(+)$ terhadap disiplin kerja pegawai Dinas Kependudukan Dan Pencatatan Sipil Kab. Temanggung.

\section{Pengaruh Motivasi Terhadap Disiplin Kerja}

Motivasi disini juga bisa dari luar atau motivasi ekstrinsik, adalah keinginan seseorang untuk melakukan sesuatu yang disebabkan oleh faktor dorongan dari luar diri sendiri untuk mencapai suatu tujuan yang menguntungkan dirinya. Motivasi adalah energy yang menggerakkan individu untuk berusaha mencapai tujuan yang diharapkan (Sulistiyani dan Rosidah, 2009:76). Dengan demikian, apabila dikaitkan dengan instansi atau tempat bekerja, motivasi berperan penting dalam instansi, karena apabila tidak adanya motivasi atau dorongan semangat terhadap pegawai Dinduk Capil, kemungkinan dapat mempengaruhi tingkat disiplin kerja pegawai tersebut, sebaliknya apabila pegawai Dinduk Capil tersebut termotivasi atau mendapat dorongat semangat, maka berkemungkinan juga dapat meningkatkan tingkat disiplin dalam bekerja.

H2: Motivasi kerja Ekstrinsik diduga berpengaruh signifikan positif (+) terhadap disiplin kerja Dinas Kependudukan Dan Pencatatan Sipil Kab. Temanggung.

\section{Pengaruh Lingkungan Terhadap Kepuasan Kerja}

Menurut Supardi (2003:37), menyatakan bahwa lingkungan kerja merupakan keadaan sekitar tempat kerja baik secara fisik maupun non fisik yang dapat memberikan kesan menyenangkan, mengamankan, menentramkan dan kesan betah bekerja dan lain sebagainya. Lingkungan kerja dikatakan baik atau sesuai apabila manusia dapat melaksanakan kegiatan secara optimal, sehat, aman dan nyaman.

H3: Lingkungan kerja diduga berpengaruh signifikan positif (+) terhadap kepuasan kerja pegawai Dinas Kependudukan Dan Pencatatan Sipil Kab. Temanggung.

\section{Pengaruh Motivasi Terhadap Kepuasan Kerja}

Motivasi adalah energy yang menggerakkan individu untuk berusaha mencapai tujuan yang diharapkan (Sulistiyani dan Rosidah, 2009:76). Dengan demikian, apabila dikaitkan dengan instansi atau tempat bekerja, motivasi berperan penting dalam instansi, karena apabila tidak adanya motivasi atau dorongan semangat terhadap pegawai Dinduk Capil, kemungkinan dapat mempengaruhi tingkat kepuasan kerja pegawai tersebut, sebaliknya apabila pegawai Dinduk Capil tersebut termotivasi atau mendapat dorongat semangat, maka berkemungkinan juga dapat meningkatkan tingkat kepuasan dalam bekerja.

H4: Motivasi kerja Ekstrinsik diduga berpengaruh signifikan positif (+) terhadap kepuasan kerja Dinas Kependudukan Dan Pencatatan Sipil Kab. Temanggung.

\section{Pengaruh Kepuasan Terhadap Disiplin Kerja}

Hasibuan (2006:39) mendefinisikan kepuasan kerja adalah sikap emosional yang menyenangkan dan mencintai pekerjaannya. Sikap ini dicerminkan oleh moral kerja, kedisiplinan, dan prestasi kerja. Kepuasan kerja dinikmati dalam pekerjaan, luar pekerjaan, dan kombinasi antara keduanya. Dengan demikian, dapat disimpulkan bahwa seorang individu atau karyawan apabila dalam melakukan pekerjaannya dengan rasa senang, nyaman tanpa suatu tekanan, dapat mempengaruhi dan berperan dalam meningkatkannya tingkat disiplin kerja Dinas Kependudukan Dan Pencatatan Sipil Kab. Temanggung.

H5: Kepuasan kerja karyawan diduga berpengaruh signifikan positif $(+)$ 
Terhadap Tingkat Disiplin kerja pegawai Dinas Kependudukan Dan Pencatatan Sipil Kab. Temanggung.

\section{METODE PENELITIAN}

Penelitian yang digunakan adalah Kuantitatif deskriptif. Suatu proses menemukan pengetahuan yang menggunakan data berupa angka sebagai alat menganalisis keterangan mengenai apa yang ingin diketahui. Kasiram (2008: 149) dalam bukunya Metodologi Penelitian Kualitatif dan Kuantitatif). Sehingga maksud dari penelitian ini untuk menggambarkan suatu keadaan obyek tertentu yang memiliki hubungan atau dipengaruhi faktor lain dan penarikan kesimpulan berdasarkan dengan angka yang diolah secara statistik.

(Arikunto, 2006: 12). Pengumpulan data yang digunakan adalah secara primer atau menyebar angket pada narasumber. Tujuannya adalah untuk menggambarkan mengungkapkan fakta secara lebih mendalam mengenai hubungan antara peran lingkungan, motivasi dan kepuasan kerja terhadap disiplin kerja pegawai Dinas Kependudukan Dan Pencatatan Sipil Kab. Temanggung.

\section{HASIL DAN PEMBAHASAN}

Tabel 1. Data Responden Berdasarkan Gender/kelamin

\begin{tabular}{cccc}
\hline No & Variabel & Frequency & Valid Percent \\
\hline 1 & Laki-laki & 20 & 43,5 \\
2 & Perempuan & 26 & 56,5 \\
& Total & 46 & 100 \\
\hline
\end{tabular}

Sumber data : diolah 2020

Berdasarkan tabel 1 diketahui bahwa responden perempuan 56,5\% sedangkan responden lakilaki sebanyak $43,5 \%$. Hal tersebut membuktikan bahwa kuisioner dalam penelitian ini di dominasi oleh pegawai perempuan.

Tabel 2. Data Responden Berdasarkan Usia

\begin{tabular}{cccc}
\hline No & Variabel & Frequency & Valid Percent \\
\hline 1 & $21-30$ & 19 & 41,3 \\
2 & $31-44$ & 16 & 34,8 \\
3 & $45-57$ & 11 & 23,9 \\
& Total & 46 & 100 \\
\hline
\end{tabular}

Sumber data : diolah 2019

Berdasarkan tabel 2 menunjukkan bahwa responden dengan usia 21-30 sebanyak 19, responden dengan usia 31-44 sebanyak 16, dan responden dengan usia 45-57 tahun sebanyak 11.

Tabel 3. Data Responden Berdasarkan Pendidikan Terakhir

\begin{tabular}{cccc}
\hline No & Variabel & Frequency & Valid Percent \\
\hline 1 & S2 & 3 & 6,5 \\
2 & S1 & 24 & 52,2 \\
3 & Diploma & 9 & 19,6 \\
4 & SMA/SMK & 9 & 19,6 \\
5 & SMP & 1 & 2,2 \\
& Total & 46 & 100 \\
\hline
\end{tabular}

Sumber data : diolah 2020

Berdasarkan Tabel 3 Menunjukkan bahwa responden dengan dengan tingkat pendidikan S2 sebanyak 3, responden dengan tingkat pendidikan S1 sebanyak 24, responden dengan tingkat 
pendidikan Diploma sebanyak 9, responden dengan tingkat pendidikan SMA/SMK sebanyak 9 dan responden dengan tingkat pendidikan SMP sebanyak 1.

Tabel 4. Hasil Uji Validitas Lingkungan kerja

\begin{tabular}{cllll}
\hline Variabel & Butir & r-hitung & r-tabel & keterangan \\
\hline & & & & \\
& L1 & 0,461 & 0,291 & Valid \\
& L2 & 0,771 & 0,291 & Valid \\
Lingkungan & L3 & 0,376 & 0,291 & Valid \\
& L5 & 0,404 & 0,291 & Valid \\
& L5 & 0,618 & 0,291 & Valid \\
& L6 & 0,357 & 0,291 & Valid \\
\hline
\end{tabular}

Sumber data : diolah 2020

Tabel 4 diatas menunjukan bahwa semua butir pernyataan pada variabel lingkungan kerja mempunyai nilai r-hitung lebih besar dari r-tabel untuk $\mathrm{n}=60$ dan $\alpha=5 \%$, sebesar 0,291 (dikarenakan butir kuisioner yang kembali sebanyak 50 responden dan menggunakan tabel Cohen Manion dan Morrison . Semua item variabel lingkugan kerja adalah valid dan dapat digunakan untuk penelitian ini. Adapun uji validitas untuk motivasi ekstrinsik (X2) pada tabel berikut ini.

Tabel 5. Hasil Uji Validitas Motivasi kerja

\begin{tabular}{ccccc}
\hline Variabel & Butir & r-hitung & r-tabel & keterangan \\
\hline & M 1 & 0,448 & 0,291 & Valid \\
& M 2 & 0,541 & 0,291 & Valid \\
Motivasi Eks & M 3 & 0,375 & 0,291 & Valid \\
& M 4 & 0,533 & 0,291 & Valid \\
& M 5 & 0,631 & 0,291 & Valid \\
& M 6 & 0,527 & 0,291 & Valid \\
& M 7 & 0,457 & 0,291 & Valid \\
\hline
\end{tabular}

Sumber data : diolah 2020

Tabel 5 diatas menunjukan bahwa semua butir pernyataan pada variabel motivasi kerja mempunyai nilai $r$-hitung lebih besar dari r-tabel untuk $\mathrm{n}=60$ dan $\alpha=5 \%$, sebesar 0,291 (dikarenakan butir kuisioner yang kembali sebanyak 50 responden dan menggunakan tabel Cohen Manion dan Morrison (2007). Semua item variabel motivasi kerja adalah valid dan dapat digunakan untuk penelitian berikutnya. Adapun uji validitas untuk kepuasan kerja (Z).

Tabel 6. Hasil Uji Validitas Kepuasan kerja

\begin{tabular}{cllll}
\hline Variabel & Butir & r-hitung & r-tabel & keterangan \\
\hline \multirow{5}{*}{ Kepuasan } & KP 1 & 0,576 & 0,291 & Valid \\
& KP 2 & 0,483 & 0,291 & Valid \\
& KP 3 & 0,706 & 0,291 & Valid \\
& KP 4 & 0,339 & 0,291 & Valid \\
& KP 5 & 0,706 & 0,291 & Valid \\
& KP 6 & 0,417 & 0,291 & Valid \\
\hline
\end{tabular}

Sumber data : diolah 2020

Tabel 6 diatas menunjukan bahwa semua butir pernyataan pada variabel motivasi kerja mempunyai nilai r-hitung lebih besar dari r-tabel untuk $\mathrm{n}=60-2=58$ dan $\alpha=5 \%$, sebesar 0,291 (dikarenakan butir kuisioner yang kembali sebanyak 50 responden dan menggunakan 
tabel Cohen Manion dan Morrison. Semua item variabel kepuasan kerja adalah valid dan dapat digunakan untuk penelitian berikutnya. Adapun uji validitas untuk disiplin kerja (Y).

Tabel 7. Hasil Uji Validitas Disiplin kerja

\begin{tabular}{ccccc}
\hline Variabel & Butir & r-hitung & r-tabel & keterangan \\
\hline \multirow{5}{*}{ Disiplin } & & & & \\
& D 1 & 0,402 & 0,291 & Valid \\
& D 2 & 0,468 & 0,291 & Valid \\
& D 3 & 0,397 & 0,291 & Valid \\
& D 4 & 0,397 & 0,291 & Valid \\
& D 5 & 0,549 & 0,291 & Valid \\
& D 6 & 0,478 & 0,291 & Valid \\
& D 7 & 0,307 & 0,291 & Valid \\
& D 8 & 0,548 & 0,291 & Valid \\
\hline
\end{tabular}

Sumber data : diolah 2020 (lampiran 5)

Tabel 7 diatas menunjukan bahwa semua butir pernyataan pada variabel motivasi kerja mempunyai nilai r-hitung lebih besar dari r-tabel untuk $\mathrm{n}=60$ dan $\alpha=5 \%$, sebesar 0,291 (dikarenakan butir kuisioner yang kembali sebanyak 50 responden dan menggunakan tabel Cohen Manion dan Morrison. Maka semua item variabel disiplin kerja adalah valid dan dapat digunakan untuk penelitian berikutnya.

Tabel 8. Hasil Uji Reliabilitas

\begin{tabular}{cccc}
\hline No & Variabel & Cronbach's alpha & Keterangan \\
\hline 1 & Lingkungan Kerja & 0,748 & Reliabel \\
2 & Motivasi Ekstrinsik & 0,773 & Reliabel \\
3 & Kepuasan Kerja & 0,778 & Reliabel \\
4 & Disiplin Kerja & 0,742 & Reliabel \\
\hline
\end{tabular}

Sumber data : diolah 2020

Tabel 9. Hasil Uji Normalitas $X 1, X 2 \rightarrow Z$ (intervening) One-Sample Kolmogorov-Smirnov Test

Unstandardized Residual

\begin{tabular}{llr}
\hline $\mathrm{N}$ & & \multicolumn{2}{c}{ Residual } \\
\hline Normal Parameters & & 46 \\
& Mean &, 0000000 \\
\cline { 2 - 3 } Most Extreme Differences & Std. Deviation & 2,26962480 \\
\cline { 2 - 3 } & Absolute &, 092 \\
\cline { 2 - 3 } & Positive &, 092 \\
\cline { 2 - 3 } & Negative &,- 064 \\
\hline Test Statistic & &, 092 \\
\hline Asymp. Sig. (2-tailed) & &, $200^{\mathrm{c}, \mathrm{d}}$ \\
\hline
\end{tabular}

a. Test distribution is Normal.

b. Calculated from data.

c. Lilliefors Significance Correction.

$\mathrm{d}$. This is a lower bound of the true significance.

Sumber data : diolah 2020 


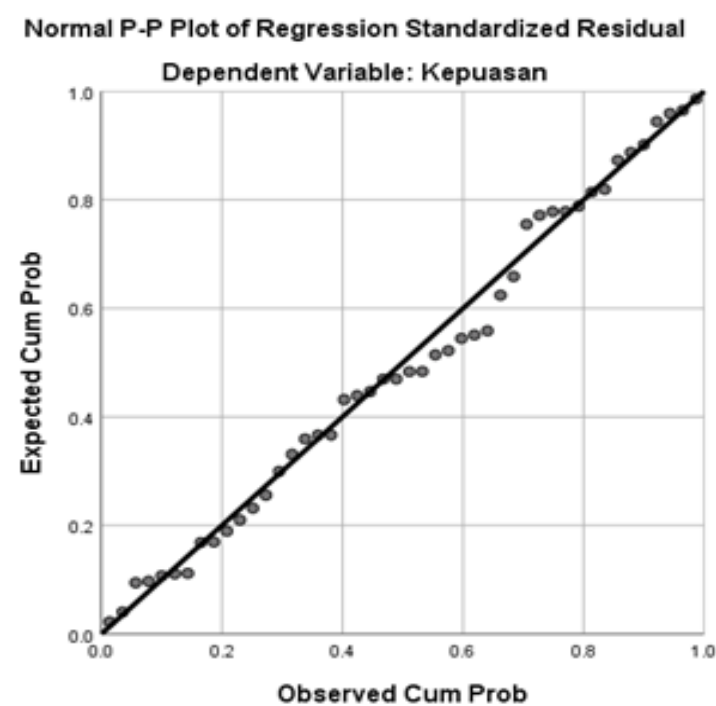

Gambar 1. Grafik Hasil Uji Normalitas (Kepuasan)

Tabel 10. Hasil Uji Normalitas X1, X2 dan Z $\rightarrow$ Y One-Sample Kolmogorov-Smirnov Test

Unstandardized

Residual

\begin{tabular}{llr}
\hline $\mathrm{N}$ & & 46 \\
\hline Normal Parameters & Mean &, 0000000 \\
\cline { 2 - 3 } & Std. Deviation & 2,12943782 \\
\hline Most Extreme Differences & Absolute &, 101 \\
\cline { 2 - 3 } & Positive &, 101 \\
\cline { 2 - 3 } & Negative &,- 075 \\
\hline Test Statistic & &, 101 \\
\hline Asymp. Sig. (2-tailed) & &, $200^{\text {c,d }}$ \\
\hline
\end{tabular}

a. Test distribution is Normal.

b. Calculated from data.

c. Lilliefors Significance Correction.

$\mathrm{d}$. This is a lower bound of the true significance.

Sumber data : diolah 2020

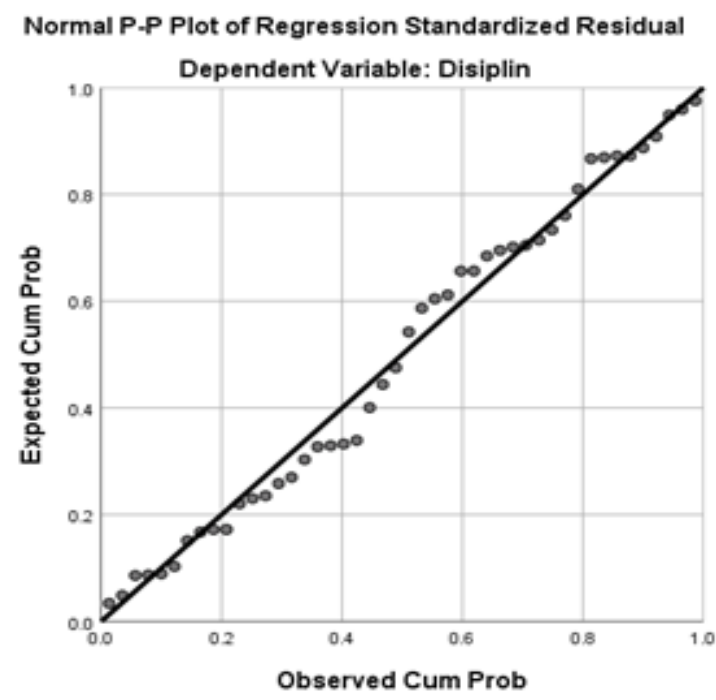

Gambar 2. Grafik Hasil Uji Normalitas (Disiplin) 


\begin{tabular}{|c|c|c|c|c|c|c|c|c|}
\hline \multirow{3}{*}{\multicolumn{2}{|c|}{ Model }} & \multirow{2}{*}{\multicolumn{2}{|c|}{$\begin{array}{c}\text { Unstandardized } \\
\text { Coefficients }\end{array}$}} & \multirow{3}{*}{$\begin{array}{l}\text { Coefficients }^{\mathbf{a}} \\
\text { Standardized } \\
\text { Coefficients } \\
\text { Beta }\end{array}$} & \multirow[b]{3}{*}{$\mathrm{t}$} & \multirow[b]{3}{*}{ Sig. } & \multirow{2}{*}{\multicolumn{2}{|c|}{$\begin{array}{l}\text { Collinearity } \\
\text { Statistics }\end{array}$}} \\
\hline & & & & & & & & \\
\hline & & B & Std. Error & & & & Tolerance & VIF \\
\hline \multirow[t]{3}{*}{1} & (Constant) & 22,964 & 4,915 & & 4,672 & ,000 & & \\
\hline & Lingkungan &,- 348 & ,151 &,- 322 & $-2,309$ & ,026 & ,948 & 1,054 \\
\hline & Motivasi & ,393 & ,135 & ,405 & 2,909 & ,006 & ,948 & 1,054 \\
\hline
\end{tabular}

a. Dependent Variable: Kepuasan

Sumber data : diolah 2020

Tabel 12. Uji Multikolinearitas X1, X2 dan X3 $\rightarrow$ Y

Coefficients $^{\mathrm{a}}$

Standardized

Unstandardized

Coefficients

\begin{tabular}{|c|c|c|c|c|c|c|c|c|}
\hline \multirow{2}{*}{\multicolumn{2}{|c|}{ Model }} & \multicolumn{2}{|c|}{ Coefficients } & \multirow{2}{*}{$\begin{array}{c}\text { Coefficients } \\
\text { Beta } \\
\end{array}$} & \multirow[b]{2}{*}{$\mathrm{t}$} & \multirow[b]{2}{*}{ Sig. } & \multicolumn{2}{|c|}{ Collinearity Statistics } \\
\hline & & $\mathrm{B}$ & Std. Error & & & & Tolerance & VIF \\
\hline 1 & (Constant) & 14.595 & 5.729 & & 2.547 & .015 & & \\
\hline & Lingkungan & 175 & .152 & 165 & 1.156 & 254 & .844 & 1.185 \\
\hline & Motivasi & 226 & 140 & 237 & 1.608 & .115 & .792 & 1.262 \\
\hline & Kepuasan & .378 & .145 & .384 & 2.613 & .012 & .791 & 1.263 \\
\hline
\end{tabular}

a. Dependent Variable: Disiplin

Sumber data : diolah 2020

Tabel 13. Hasil Uji Heterokedastisitas (Metode Gletser) X1, X2 $\rightarrow$ Z Coefficients $^{\mathrm{a}}$

\begin{tabular}{|c|c|c|c|c|c|c|}
\hline \multirow{2}{*}{\multicolumn{2}{|c|}{ Model }} & \multicolumn{2}{|c|}{ Unstandardized Coeffic } & \multirow{2}{*}{$\begin{array}{c}\text { Standardized } \\
\text { Coefficients } \\
\text { Beta }\end{array}$} & \multirow[b]{2}{*}{$\mathrm{t}$} & \multirow[b]{2}{*}{ Sig. } \\
\hline & & B & Std. Error & & & \\
\hline \multirow[t]{3}{*}{1} & (Constant) & -,679 & 2,932 & &,- 232 & 818 \\
\hline & Lingkungan & ,012 & ,090 & ,021 & ,136 & 892 \\
\hline & Motivasi & 072 & 081 & 139 & 899 & 374 \\
\hline
\end{tabular}

a. Dependent Variable: RES2

Sumber data : diolah 2020

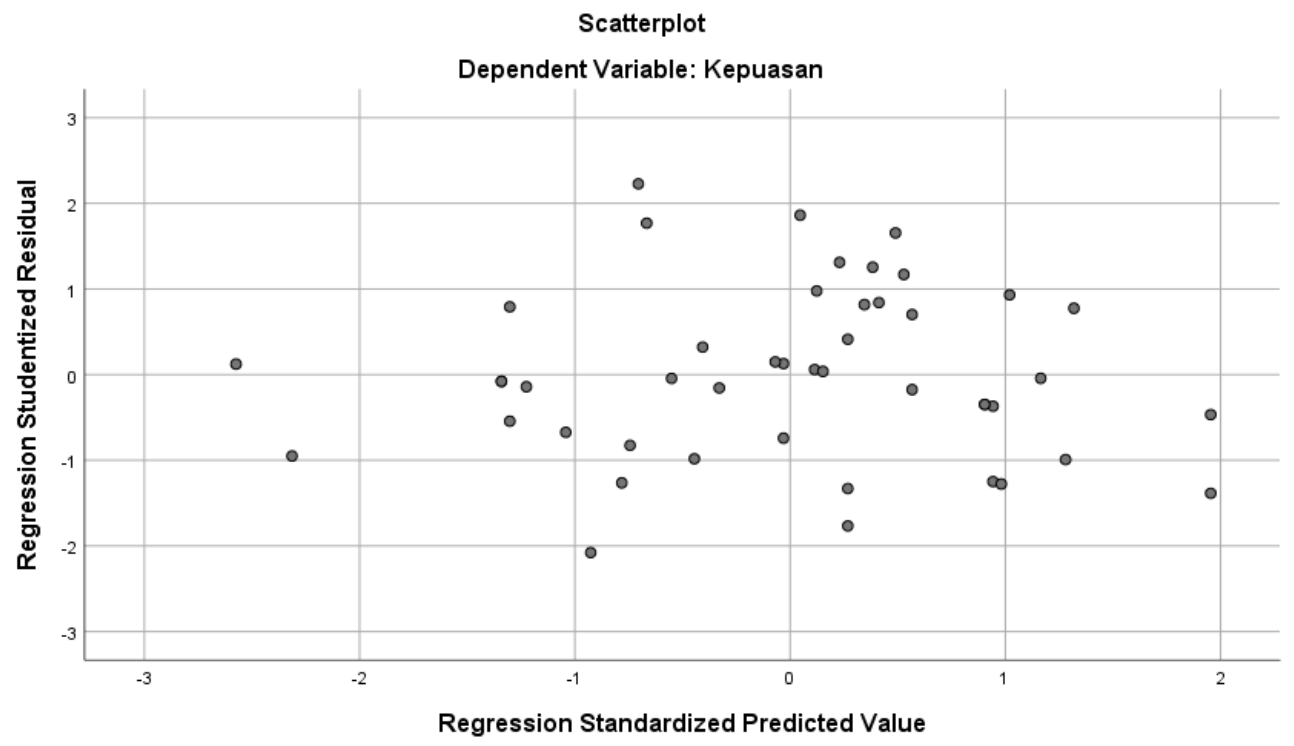

Gambar 3. Grafik Scatterplot (Kepuasan) 


\begin{tabular}{|c|c|c|c|c|c|c|}
\hline \multirow[b]{2}{*}{ Mod } & & \multicolumn{2}{|c|}{ Unstandardized Coefficients } & \multirow{2}{*}{$\begin{array}{c}\text { Standardized } \\
\text { Coefficients } \\
\text { Beta }\end{array}$} & \multirow[b]{2}{*}{$\mathrm{t}$} & \multirow[b]{2}{*}{ Sig. } \\
\hline & & B & Std. Error & & & \\
\hline \multirow[t]{4}{*}{1} & (Constant) &,- 535 & 2,568 & &,- 208 & ,836 \\
\hline & Lingkungan & ,009 & ,068 & ,020 & 133 & 895 \\
\hline & Motivasi & ,191 & ,063 & ,463 & 3,043 & ,004 \\
\hline & Kepuasan &,- 139 & ,065 &,- 327 & $-2,144$ & ,038 \\
\hline
\end{tabular}

a. Dependent Variable: RES2

Sumber data : diolah 2020

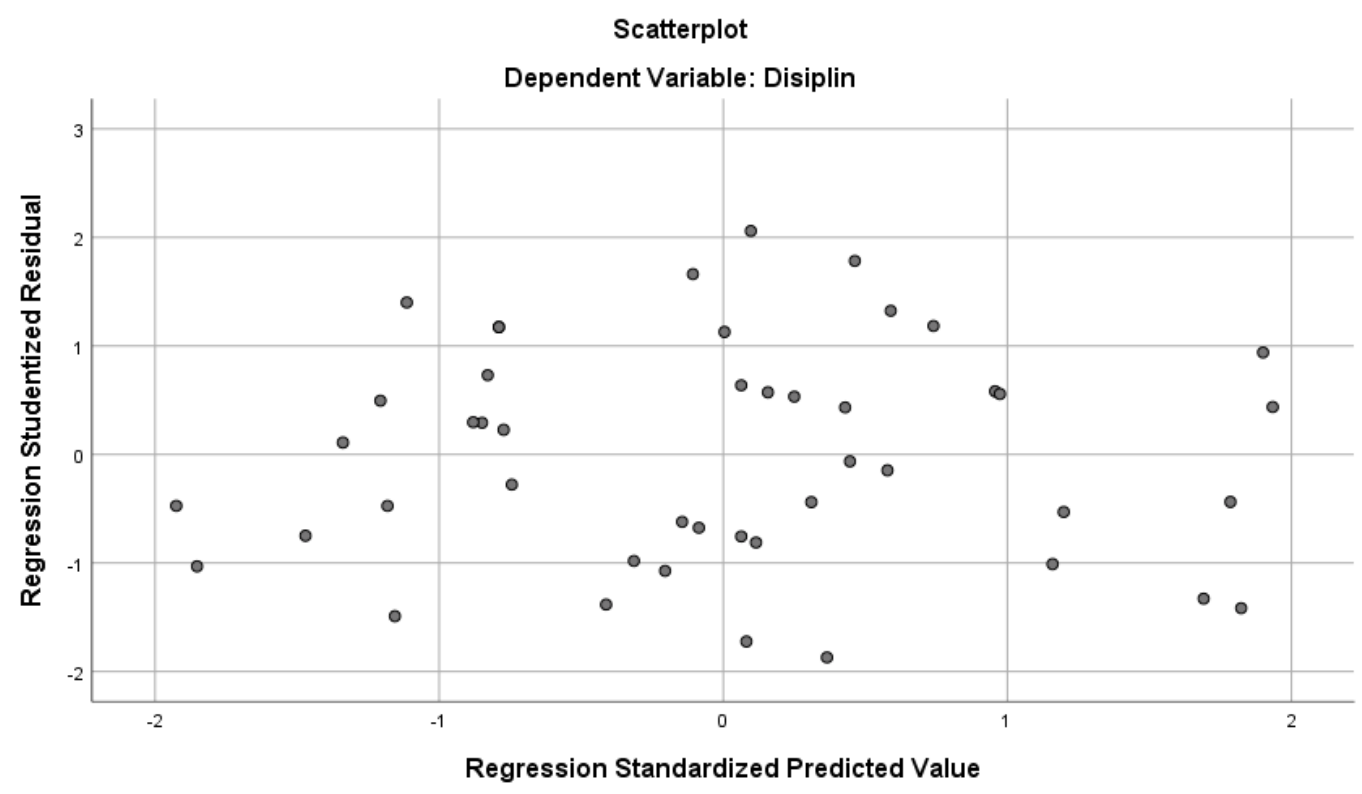

Gambar 4. Grafik Scatterplot (Disiplin)

\section{Uji Hipotesis Data}

\section{Hasil Analisis Regresi Uji t}

Uji t digunakan untuk menguji apakah masing-masing variabel bebas berpengaruh secara signifikan terhadap variabel terikat secara parsial $\alpha=0,05$.

Tabel 15.Hasil Regresi X1, X2, Z $\rightarrow$ Y

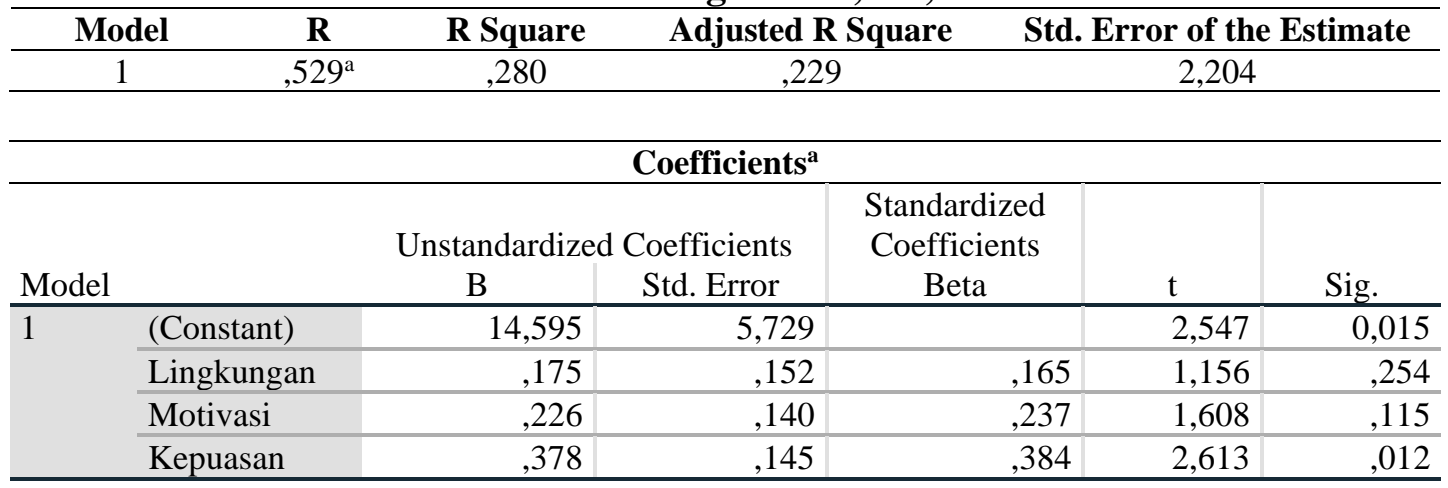

a. Dependent Variable: RES2

Sumber data : diolah 2020 
Tabel 16. Hasil Regresi X1, X2 $\rightarrow \mathrm{Z}$

Coefficients $^{\mathrm{a}}$

Unstandardized Coefficients

Standardized

Coefficients

\begin{tabular}{|c|c|c|c|c|c|c|}
\hline \multicolumn{2}{|c|}{ Model } & B & Std. Error & Beta & $\mathrm{t}$ & Sig. \\
\hline \multirow[t]{3}{*}{1} & (Constant) & 22,964 & 4,915 & & 4,672 &, 000 \\
\hline & Lingkungan &,- 348 & 151 &,- 322 & $-2,309$ & ,026 \\
\hline & Motivasi & ,393 & 135 & ,405 & 2,909 & ,006 \\
\hline
\end{tabular}

a. Dependent Variable: Z

Sumber data : diolah 2020

Hasil Analisis Regresi Uji F

$\mathrm{F}$ tabel $=\mathrm{F}(\mathrm{k} ; \mathrm{n}-\mathrm{k})=\mathrm{F}(3 ; 43)=2,82$ "untuk dependent $\mathrm{Y}$ "

F tabel $=F(k ; n-k)=F(2 ; 44)=3,21$ "untuk dependent $Z$ "

Ket :

$\mathrm{k}=$ jumlah var bebas /independen

$\mathrm{n}=$ jumlah sampel

\begin{tabular}{|c|c|c|c|c|c|c|}
\hline \multicolumn{7}{|c|}{ 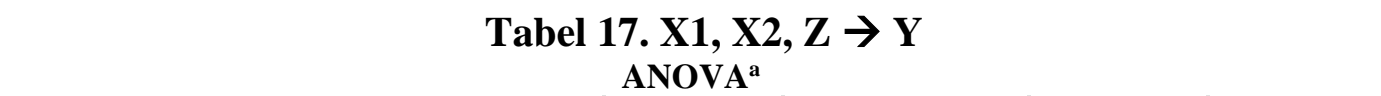 } \\
\hline Model & & Sum of Squares & Df & Mean Square & $\mathrm{F}$ & Sig. \\
\hline \multirow[t]{3}{*}{1} & Regression & 46,198 & 2 & 23,099 & 4,187 &, $022^{b}$ \\
\hline & Residual & 237,215 & 43 & $5 ., 517$ & & \\
\hline & Total & 283,413 & 45 & & & \\
\hline
\end{tabular}

a. Dependent Variable: Y

b. Predictors: (Constant), Motivasi, Lingkungan

Sumber data : diolah 2020

Tabel 18. $X 1, X 2 \rightarrow Z$

ANOVA $^{\mathrm{a}}$

\begin{tabular}{llr|r|r|r|r} 
Model & & Sum of Squares & Df & Mean Square & F & \multicolumn{1}{c}{ Sig. } \\
\hline \multirow{2}{*}{1} & Regression & 61,066 & 2 & 30,533 & 5,664 &, $007^{\mathrm{b}}$ \\
\cline { 2 - 7 } & Residual & 231,804 & 43 & 5,391 & & \\
\cline { 2 - 7 } & Total & 292,870 & 45 & & & \\
\hline
\end{tabular}

a. Dependent Variable: Z

b. Predictors: (Constant), Motivasi, Lingkungan

Sumber data : diolah 2020

\section{Analisis Jalur}

Pengaruh lingkungan kerja (X1) dan motivasi (X2) terhadap kepuasan kerja (Z)

\section{Tabel 19. Jalur Regresi Model I} Coefficients $^{\mathrm{a}}$

\section{\begin{tabular}{l|l} 
Standardized \\
Coefficients
\end{tabular}}

\begin{tabular}{|c|c|c|c|c|c|c|}
\hline \multicolumn{2}{|c|}{ Model } & $\mathrm{B}$ & Std. Error & Beta & $\mathrm{t}$ & Sig. \\
\hline \multirow[t]{3}{*}{1} & (Constant) & 22,964 & 4,915 & & 4,672 &, 000 \\
\hline & Lingkungan &,- 348 &, 151 &,- 322 & $-2,309$ & ,026 \\
\hline & Motivasi & ,393 & 135 & ,405 & 2,909 & ,006 \\
\hline
\end{tabular}

a. Dependent Variable: Z

Sumber data : diolah 2019 
Berdasarkan tabel diatas dapat dilihat dari angka standarized coefficients, besar pengaruh lingkungan kerja (X1) terhadap kepuasan kerja sebesar (Z) 0,322 atau 32,2\%, untuk motivasi kerja (X2) terhadap kepuasan kerja $(Z)$ sebesar 0,405 atau 40,5\%. Untuk nilai e1 $=\sqrt{(1-0,209)}$ sebesar 0,89 .

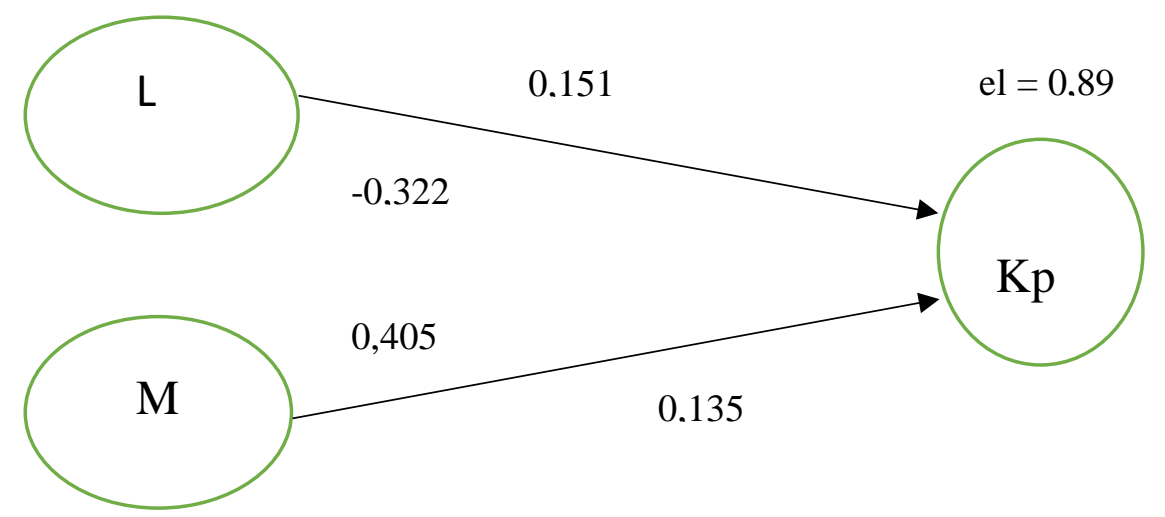

Gambar 5. Model Jalur I

\section{Regresi Model II}

Pengaruh lingkungan kerja (X1), motivasi (X2) dan kepuasan kerja (Z) terhadap disiplin kerja (Y).

\begin{tabular}{|c|c|c|c|c|c|c|}
\hline \multicolumn{7}{|c|}{$\begin{array}{c}\text { Tabel 20. Jalur Regresi Model II } \\
\text { Coefficients }^{\mathrm{a}}\end{array}$} \\
\hline & & \multicolumn{2}{|c|}{ Unstandardized Coefficients } & \multirow{2}{*}{$\begin{array}{c}\text { Standardized } \\
\text { Coefficients } \\
\text { Beta }\end{array}$} & \multirow[b]{2}{*}{$\mathrm{t}$} & \multirow[b]{2}{*}{ Sig. } \\
\hline & & B & Std. Error & & & \\
\hline \multirow[t]{4}{*}{$\overline{1}$} & (Constant) & 14,595 & 5,729 & & 2,547 &, 015 \\
\hline & Lingkungan &, 175 &, 152 &, 165 & 1,156 & ,254 \\
\hline & Motivasi & ,226 &, 140 & ,237 & 1,608 &, 115 \\
\hline & Kepuasan & ,378 &, 145 & ,384 & 2,613 & 012 \\
\hline
\end{tabular}

a. Dependent Variable: Disiplin

Sumber data : diolah 2020 (lampiran 7)

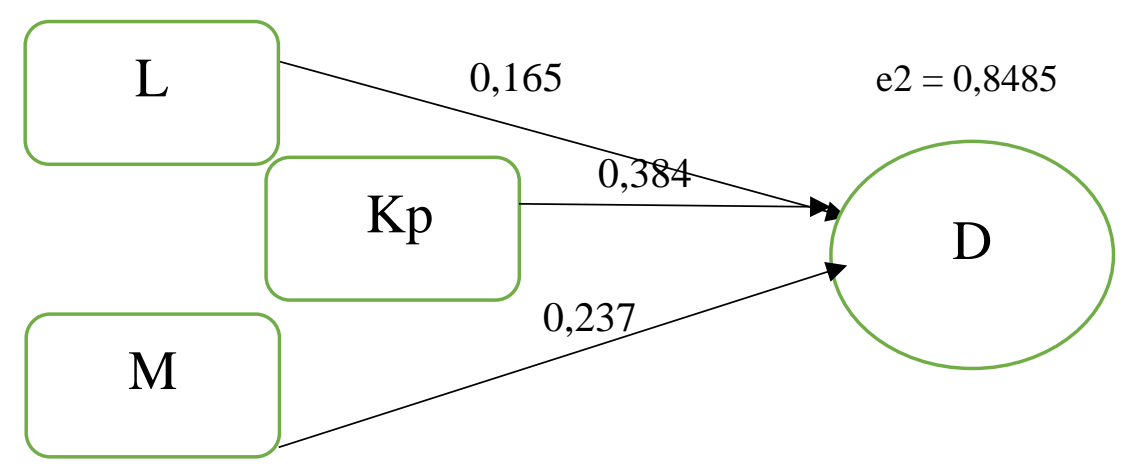

Gambar 6. Model Jalur II

\section{Jalur Model III}

Pengaruh tidak langsung lingkungan (X1) melalui kepuasan (Z) terhadap disiplin (Y) adalah perkalian antara nilai beta $(\mathrm{X} 1)$ terhadap kepuasan kerja $(\mathrm{Z})$ dengan nilai beta kepuasan kerja (Z) dengan disiplin (Y). 
$\mathrm{X} 1 \rightarrow \mathrm{Y}=(-0,322 \times 0,384)=0,1236$ atau $12,4 \%$. Jadi pengaruh tidak langsung didapatkan sebesar 0,1236 atau $12,4 \%$. Sedangkan pengaruh total yang diberikan X1 $\rightarrow$ Y adalah pengaruh langsung + pengaruh tidak langsung $=16,5 \%+12,4 \%=28,9 \%$.

$\mathrm{X} 2 \rightarrow \mathrm{Y}=(0,405 \times 0,384)=0,155$ atau $15,5 \%$. Jadi pengaruh tidak langsung didapatkan sebesar 0,155 atau $15,5 \%$. Sedangkan pengaruh total yang diberikan $\mathrm{X} 2 \rightarrow \mathrm{Y}$ adalah pengaruh langsung + pengaruh tidak langsung $=23,7 \%+15,5 \%=39,2 \%$.
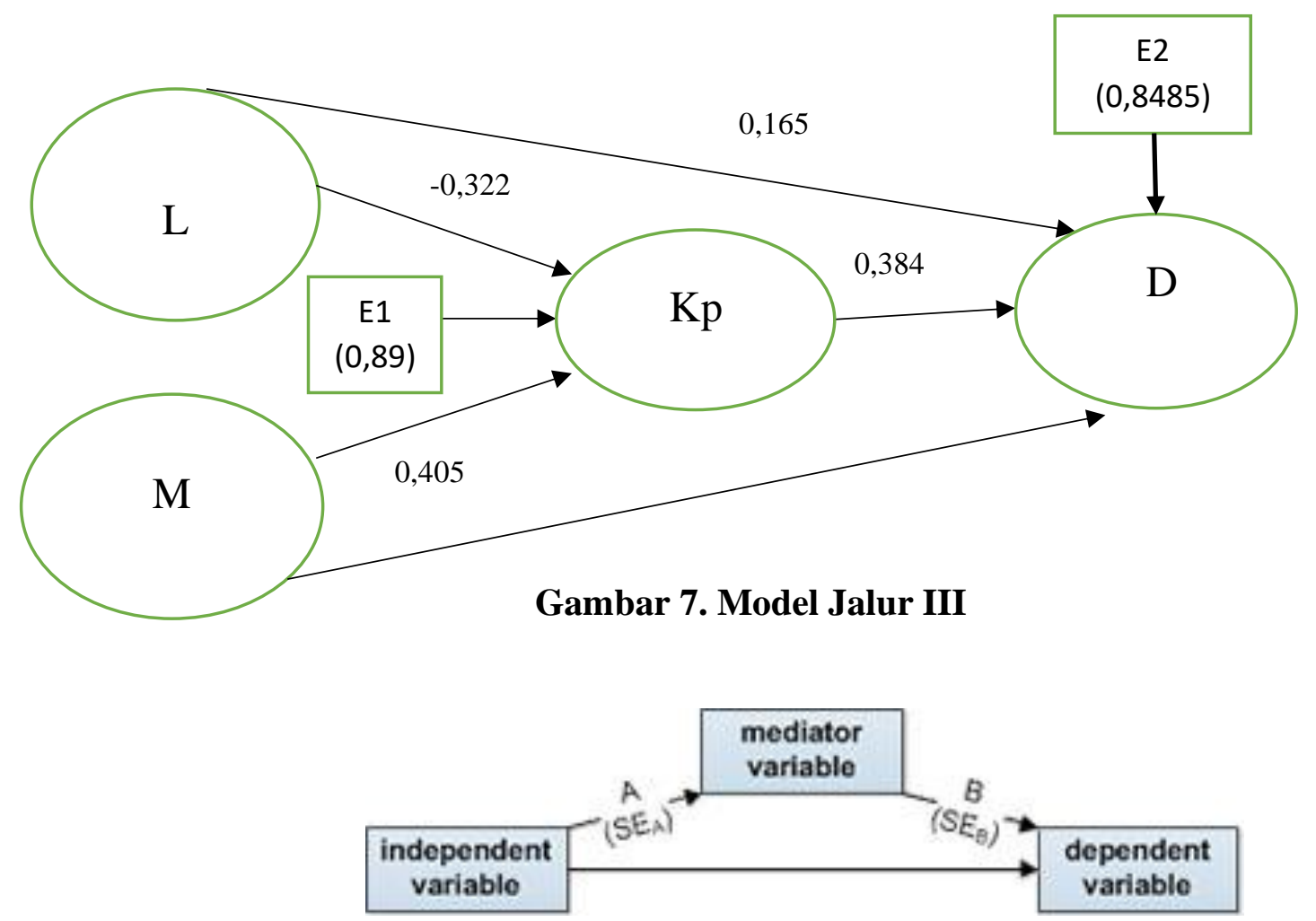

Gambar 8. Uji Sobel X1 $\rightarrow$ Y melalui Z

$\begin{array}{ll}\mathrm{a} & =0,175 \\ \mathrm{~b} & =0,378 \\ \mathrm{Sa} & =0,152 \\ \mathrm{Sb} & =0,145\end{array}$

Calculate

Sobel test statistic : 1,05317805

One-tailed probability : 0,14612970

Two-tailed probability: 0,29225940

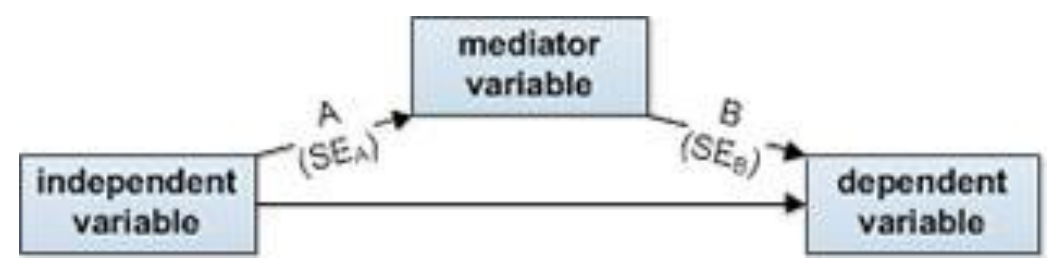

Gambar 9. Uji Sobel X2 $\rightarrow$ Y melalui Z 


$$
\begin{array}{ll}
\mathrm{a} & =0,226 \\
\mathrm{~b} & =0,378 \\
\mathrm{Sa} & =0,140 \\
\mathrm{Sb} & =0,145
\end{array}
$$

Calculate

Sobel test statistic $\quad: 1.37245480$

One-tailed probability : 0.08496095

Two-tailed probability: 0.16992190

Tabel 20. Hasil Koefisien Determinasi X1, X2 $\rightarrow(Z)$

\begin{tabular}{cccc}
\hline $\mathbf{R}$ & $\mathbf{R}$ Square & Adjusted R Square & Std. Error of the Estimate \\
\hline, $457^{\mathrm{a}}$ &, 209 &, 172 & 2,322 \\
\hline a. Predictors: (Constant), Motivasi, Lingkungan & \\
b. Dependent variable: $Z$ & &
\end{tabular}

Sumber data: diolah 2020

Dari tabel diatas nilai adjusted $\mathrm{R}$ square sebesar 0,172 . Nilai ini menunjukkan bahwa variabel lingkungan kerja, motivasi eks, memberi sumbangan sebesar 20,9\% dalam mempengaruhi kepuasan kerja (Z).

Tabel 21. Hasil Koefisien Determinasi X1, X2 dan Z $\rightarrow$ (Y)

\begin{tabular}{ccccc}
\hline Model & $\mathbf{R}$ & R Square & Adjusted R Square & Std. Error of the Estimate \\
\hline 1 &, $529^{\text {a }}$ &, 280 &, 229 & 2,204 \\
\hline a. Predictors: (Constant), kepuasan, Lingkungan, Motivasi & \\
Sumber data: diolah 2020 & &
\end{tabular}

Dari tabel diatas nilai adjusted $\mathrm{R}$ square sebesar 0,229. Nilai ini menunjukkan bahwa variabel lingkungan, motivasi eks dan kepuasan memberi sumbangan sebesar $28 \%$ dalam mempengaruhi secara stimultan atau bersama-sama terhadap disiplin kerja (Y).

\section{PENUTUP}

Kesimpulan

Berdasarkan data yang didapatkan setelah diolah kembali, maka hasil penelitian tentang hubungan antara peran lingkungan, motivasi dan kepuasan kerja terhadap disiplin kerja pegawai Dinduk Caplil Kab. Temanggung, dapat ditarik kesimpulan sebagai berikut:

Berdasarkan hasil penelitian diatas maka dapat diambil kesimpulan bahwa variabel lingkungan dan motivasi kerja tidak dapat berpengaruh secara signifikan positif terhadap disiplin kerja. Variabel lingkungan berpengaruh signifikan positif terhadap kepuasan. Variabel motivasi berpengaruh signifikan positif terhadap kepuasan. Variabel kepuasan berpengaruh signiikan positif terhadap disiplin. Variabel kepuasan tidak mempengaruhi atau memediasi hubungan lingkungan terhadap disiplin kerja.

\section{Saran}

Berdasarkan kesimpulan yang telah diperoleh dari hasil penelitian ini, maka ada beberapa saran penulis yang akan diberikanberhubungan dengan lingkungan, motivasi, dan kepuasan kerja, yanitu antara lain :

Saran untuk penelitian lanjutan, penelitian ini dapat dilakukan kembali dengan objek penelitian yang berbeda serta dengan item pertanyaan pada kuisioner yang berbeda dengan pertanyaan kuisioner penelitian lainya, guna mendapat hasil yang diharapkan. Bagi peneliti selanjutnya dapat dimanfaatkan sebagai tambahan bahan rujukan dalam melakukan penelitian yang berkaitan dengan lingkungan, motivasi dan kepusan kerja. 
Saran untuk Kantor DINDUK CAPIL Kab. Temanggung harapannya dapat lebih memperhatikan lingkungan kerja dan motivasi kerja para pegawai, karena variabel tersebut tidak berpengaruh positif dan signifikan terhadap disiplin kerja pegawai. Rata- rata keseluruhan kinerja yang dilakukan pegawai Dinduk Capil sudah baik, akan tetapi dalam hasil penelitian ini terdapat variabel lingkungan yang tidak berpengaruh dalam disiplin kerja. Apabila pegawai Dinduk Capil merasakan kepuasan dalam bekerja, harapannya dapat merasakan kesenangan, sehingga apabila ada rasa senang terhadap suatu pekerjaan kemungkinannya dalam bekerja menjadi lebih bersemangat dan disiplin dalam menjalankan tugasnya.

\section{DAFTAR PUSTAKA}

Afiyah, S.N., Djaelani, A.Q. \& Priyono, A.A., 2017. PENGARUH KOMPENSASI, LINGKUNGAN KERJA DAN MOTIVASI TERHADAP KEPUASAN KERJA KARYAWAN (Studi Kasus Pada Badan Pertanahan Nasional Kabupaten Malang). Jurnal Riset Manajemen, 0, pp.124-135.

Arikunto, S. (2006). Metode penelitian kualitatif. Jakarta: Bumi Aksara.

Fengky, N.E., Tewal, B. \& Lumanauw, B., 2011. Pengaruh Motivasi Kerja, Disiplin dan Insentif Terhadap Kepuasan Kerja Karyawan pada RSUP Prof Dr. D. Kandou Malalayang. Jurnal EMBA, 5(1), pp.1-10.

Hasibuan, M. (2006). Manajemen sumber daya manusia, Edisi Revisi. Penerbit Bumi Aksara, Jakarta.

Louis Cohen, Lawrence Manion, and Keith Morrison, Research Methods in Education, Sixth Edition (Oxon: Routledge, 2007) p. 104.

Lumentut, M.D.. \& Dotulong, L.O.., 2015. Pengaruh Motivasi, Disiplin, dan Lingkungan Kerja Terhadap Kepuasan Kerja Karyawan Pada PT. Bank SULUT Cabang Airmadidi. Jurnal EMBA, ISSN: 2303-1174, 3(1), pp.74-85.

Kasiram, M. (2008). Metode penelitian kuantitatif dan kualitatif.

Manik, S., 2017. Pengaruh Kepuasan Kerja Terhadap Disiplin Kerja Pegawai Kantor Camat Pendalian Iv Koto Kabupaten Rokan Hulu. International Journal of Social Science and Business, 1(4), p.257.

Sulistiyani, Ambar T. and Rosidah,(2009). Human Resources Manajamen, Yogyakarta: Graha Ilmu.

Supardi. 2003. Kinerja Karyawan. Ghalia Jakarta.

Sutrisno, E. (2009). Manajemen Sumber Daya Manusia, edisi pertama, cetakan pertama. Penerbit: Kencana Pranada Media Group. Jakarta.

Vera, P., \& Wahyuddin, M. (2010). Pengaruh Kepemimpinan, Motivasi, Pelatihan dan Lingkungan Kerja Terhadap Kinerja Karyawan di Perusahaan Daerah Air Minum Kota Surakarta (Doctoral dissertation, Tesis). 